\title{
Answers to a Discussion Note: On the 'Metaphor of the Metaphor'
}

\author{
Hugo Letiche, Jacco van Uden
}

Hugo Letiche

Keele University UK and the Rotterdam School of Management, Erasmus

University,

Rotterdam,

The Netherlands

Jacco van Uden

Centre for

Organizational

Learning

and Change,

Nijenrode

University,

Breukelen,The

Netherlands
Organization

Studies

1998, $19 / 6$

1029-1033

(c) 1998 EGOS

0170-8406/98

0019-0040 \$3.00

\begin{abstract}
Should a debate of the choice(s) between metaphorical investigation and epistemological realism in organizational research be prioritized as Willy McCourt called for in Organization Studies? (McCourt 1997) We argue here against doing any such thing - a 'realism' debate in organizational theory would merely be a 'red herring' (Hausman 1998). Theoretical investigation from Ricoeur to Derrida has liberated us from the need to re-visit the theme, but examination of Gareth Morgan's (and Gibson Burrell's) intellectual development, as begun by McCourt, is of interest because it reveals two very different 'realisms'. What is of interest about 'realism' is not an either/or of either 'realism' or 'constructivism', but a polyphony of the many voices ('selfs') of research.
\end{abstract}

Descriptors: metaphor, epistemology, Burrell and Morgan, realism, research methodology

\section{Realism and Metaphor}

Twenty-five years ago Paul Ricoeur amply discussed the issues raised when empirical research (in his case phenomenology) crossed swords with the metaphorical nature of language (Ricoeur 1978). While the researcher's goal is to assert that what he or she describes (has 'discovered') is 'real', epistemological rigor demands the admission of 'polysemy' and 'metaphor', which seem to threaten the researcher's ability to achieve his or her goal of asserting 'real-ness'. McCourt believes we need (close to) literal scientific language, in his terms the 'weak' version of the constructivist position, to be able to relate the 'real' (McCourt 1997). In his analysis of language and 'reality', McCourt moves back and forth between two different concepts of the role of metaphor. In the first place, metaphor can be identified in rhetoric with stylistic embellishment - i.e. the creation of images and poetic descriptions that bring 'text' to life. The role of metaphor is to catch the reader's attention and create vividness. Here, metaphor is a matter of lexis (Aristotle: 'diction'). However, metaphor can also be seen epistemologically as the means by which vocabulary can grow or change. Thanks to metaphor, language can alter and renew itself. Here metaphor has to do with mimesis (Aristotle: duplication in text of reality, the expression of human action that is already there). Ricoeur argued for 
the second position, i.e. research reports and articles, like 'all linguistic creations, would be meaningless if they did not serve the general project of letting new worlds emerge' (Ricoeur 1978: 148). Words renew themselves easily because of polysemy; in natural languages they mean more than one thing - flexibility is inherent to the semiotic entities (the 'signs' or 'expressions') that are attached to a multitude of semantic (the 'meanings' or 'content') entities (Beneviste 1973; Hjelmslev 1961). Semiotic entities 'are defined by their difference with regard to other units of the same (language, text, linguistic) system ... these entities are not related to extralinguistic realities such as things, events, properties, relations, actions, passions, or states of affairs. They are purely intralinguistic phenomena' (Ricoeur 1978: 121). Thus, meaning or the 'world revealed' is an event on the level of the sentence (the text) and not on the level of the word. The 'truth-claim' or 'reference' of research refers to the world (state of affairs) to which it tries to point. Scientific language can try and repress polysemy by delimiting the semantic field of the words it uses; it can try to control the meaning of the words used (for instance in mathesis). However, research in organizational studies rarely breaks the link with natural language - it deals with companies, managements, workers, profit and loss, leadership, motives, etc., which are all present in natural language. The epistemological problem of natural science, that theory is often counter-intuitive and expressed in 'text' that is highly foreign to natural language, just does not arise (Hausman 1998). Nor does the behaviourist rupture with natural language frequently occur: 'behaviourists insist that one stick with generalizations cast at the level of observation' (Hausman 1998: 17). Organizational studies try to explain and predict, making use of categories (though often under dispute) of social phenomena that really stick quite closely to the discourse of practitioners in the field. The study of organizations welcomes theorizing concerning matters of observation. Epistemologically, the theorizing can be as speculative and bizarre (i.e. as metaphorical) as the researcher wants, as long as it has explanatory value. Researchers in organization, including even the most radical social constructivist, will admit that a discourse about 'organization' (whatever that discourse might mean) exists/existed prior to investigation. Organizational researchers de facto assume that the concept(s) of 'organization' they 'observe' in the field exist independently of the researcher(s) and can be studied. Such (a minimal) realism is only challenged by those who assume 'underlying structures, powers, mechanisms and tendencies exist, whether or not detected, [that] govern or facilitate actual events' (Lawson 1997: 21). The dissenters are transcendental realists - their assumption of depth level order is metaphysical. All the rest of us are local realists - we assume that our texts (sentences) point to a circumstance, place and event, that we can (however partially) investigate. Thus, there is very little contextually neutral text in organizational studies. McCourt does not want to accept the logic of local realism - of context-bound sentences (texts) which communicate pragmatically, i.e. of an instrumentalist OT which exists interactively, and in relationship to its stakeholders' (actors') goals and needs. McCourt wants 
a so-called langue bien faite 'ruled by the principle of a one-to-one relation between signs and entities, of one meaning for each word ... [aspiring to] a language which would be the exact picture of the structure of facts' (Ricoeur 1978: 129). McCourt pretends that his problem is with polysemy and the creative role of the metaphor in generating ever more polysemy, but his problem is broader; he doesn't accept doing (social) science in ordinary language.

Ricoeur stressed the creative ability of ordinary language to let new worlds emerge - concrete research is situated in real circumstances that can be described and theorized in (virtually) ordinary language. The role of metaphor (a new phrase, comparison, description, neologism) is to help us let new worlds (circumstances) emerge. Though just as metaphor adds meaning, language constantly becomes sedimented in routine and undergoes progressive erosion and the exhaustion of meaning. Metaphor is 'the general process by which we grasp kinship, break the distance between remote ideas, build similarities on dissimilarities ... Metaphor has the extraordinary power of redescribing reality ... [its strategy of language is] to shatter and to increase our sense of reality by shattering and increasing our language' (Ricoeur 1978: 133). While Ricoeur stresses the generativity of language, Derrida points to its usure - it is being used-up and/or attracts too much attention (Derrida 1982). The difference between living and dead metaphors is that the former renews language and is open to event and circumstance, and the latter rigidifies meaning and is closed to the local, specific and empirical. The metaphor is doomed to lose its power - it loses its brilliance and picturesqueness - the image is reduced to the schema, only to become analogy and white mythology. (Derrida 1978, paraphrased from pages 212-213) Derrida's article 'White Mythology' is, thus, about the collapse of metaphor into dead text, i.e. the erasing of the originatory event into sedimented concepts. McCourt has got it all wrong: our problem is not that metaphors disturb meaning, but that meaning deteriorates into semantic normalcy. Following Derrida's reasoning, metaphors do create a provisional loss of meaning but do not cause irreparable damage when they make their inevitable detour towards new sights / horizons. Metaphors are a part of the circular (hermeneutic) reappropriation of (ordinary language) meaning (Derrida 1978: 270), and carry their own death within them because normal semantic work, via observation, conceptualization and consciousness always takes over/prevails. Metaphor is a generative moment in the creation of meaning that achieves realism by destabilizing semantic convention(s). McCourt is wrong to oppose realism to metaphor; realism has to escape semantic embeddedness (rigidity) if its descriptions are to rise above mere 'commonplaces'. In short: what McCourt calls literal descriptions are actually coagulated or dead metaphors. If we allow ourselves to be restricted by the foci of these reality-configuring textual constructions by judging new metaphors on the extent to which they correspond with the old metaphors, then, indeed, new and liberating thinking on organizations is unlikely to occur. 


\section{The Metaphors of Burrell and Morgan}

McCourt seems to have glimpsed the problem of Gareth Morgan; Morgan has not created metaphors, but imposed a series of analogies or comparisons. Morgan wished to maintain a strict distinction between the 'objects' he compared. In his own words: 'In essence [Images of Organization] explored a series of 'what if...?' questions: What if we think about organizations as machines? What if we think about them as organisms' (Morgan 1993: 280). To paraphrase Morgan, the aim in Images of Organization was to examine the following: ' what if organisations are not-organisations, bearing in mind, of course, that organisations are organisations and not machines or organisms'. As such, the properties of the two objects (organizations/ machines; organizations/organisms) remain unaffected and new ways of conceptualizing either of them will not emerge. Morgan can be accused of creating and maintaining an epistemology wherein organization and nonorganization cannot penetrate or alter one another - new meanings are blocked from emerging. The use of metaphors, on the other hand, does allow for new routes to be taken. Metaphors of organization would be strong memorable descriptions of event, which offer the reader worlds not (clearly/ already) known in unsettling and new language. In contrast, Morgan has created a 'categorization machine' based on conceptual analogies (comparisons). There is no local realism in Images of Organization, but what Derrida calls white mythology - an anaemic conceptualization (of organization), which pretends to reveal hidden order (structure) and is, thus, more metaphysical than phenomenal. In Morgan, the normal categories of Modernist observation - conceptualization and consciousness - attempt to totally appropriate organization as a field of study. In the sense of this essay, there is hardly a metaphor to be found anywhere in the book. If, on the other hand, we go back to Burrell and Morgan's Sociological Paradigms (1979) or forward to Burrell's Pandemonium (1996), the case is different. In the former publication, the division of knowledge into a political ('radical' versus 'regulating') and a cognitive ('subjective' versus 'objective') field, was a powerful metaphor. However, the categorization of (sociological) researchers into the four resulting quadrants was highly 'regulatory' and had little or no metaphorical power. The incommensurability of research paradigms was a powerful metaphor - pigeonholing people in quadrants was not. ${ }^{1}$ Morgan went on with categorization, now by analogy, as the key activity in Images of Organization. It is Burrell who has reemerged with a new powerful metaphor in his book Pandemonium - a description of retrograde organizing. In Burrell's text, organization moves backwards in time (towards the peasant society), away from (pre-)determined 'end(s)' back to its 'beginning(s)', and away from the enlightenment (expunging itself from 'order'). While the Burrell and Morgan metaphor, of politics and cognitive style, took off almost immediately, Burrell's metaphor of logical reversal leading away from Modernist rationality, has not done so. The problem with metaphors is that there is no meta-metaphor to tell us which metaphor will prevail and why. The indeterminacy of the 
metaphor is both its strength (freedom) and limitation, but, whatever the limits of Gareth Morgan's thought may be, daring to stake out new metaphors does not seem to be especially characteristic of him. What McCourt needs to realize is that organizational research needs more rather than fewer metaphors. In other words, organization studies are much more endangered by semantic conformity and conceptual dullness than they are by epistemological chaos.

Note

1. We wish to acknowledge frequent discussions on this theme with drs. Juup Essers of the Department of Research Methodology of the School of Management, Erasmus University, Rotterdam, The Netherlands.

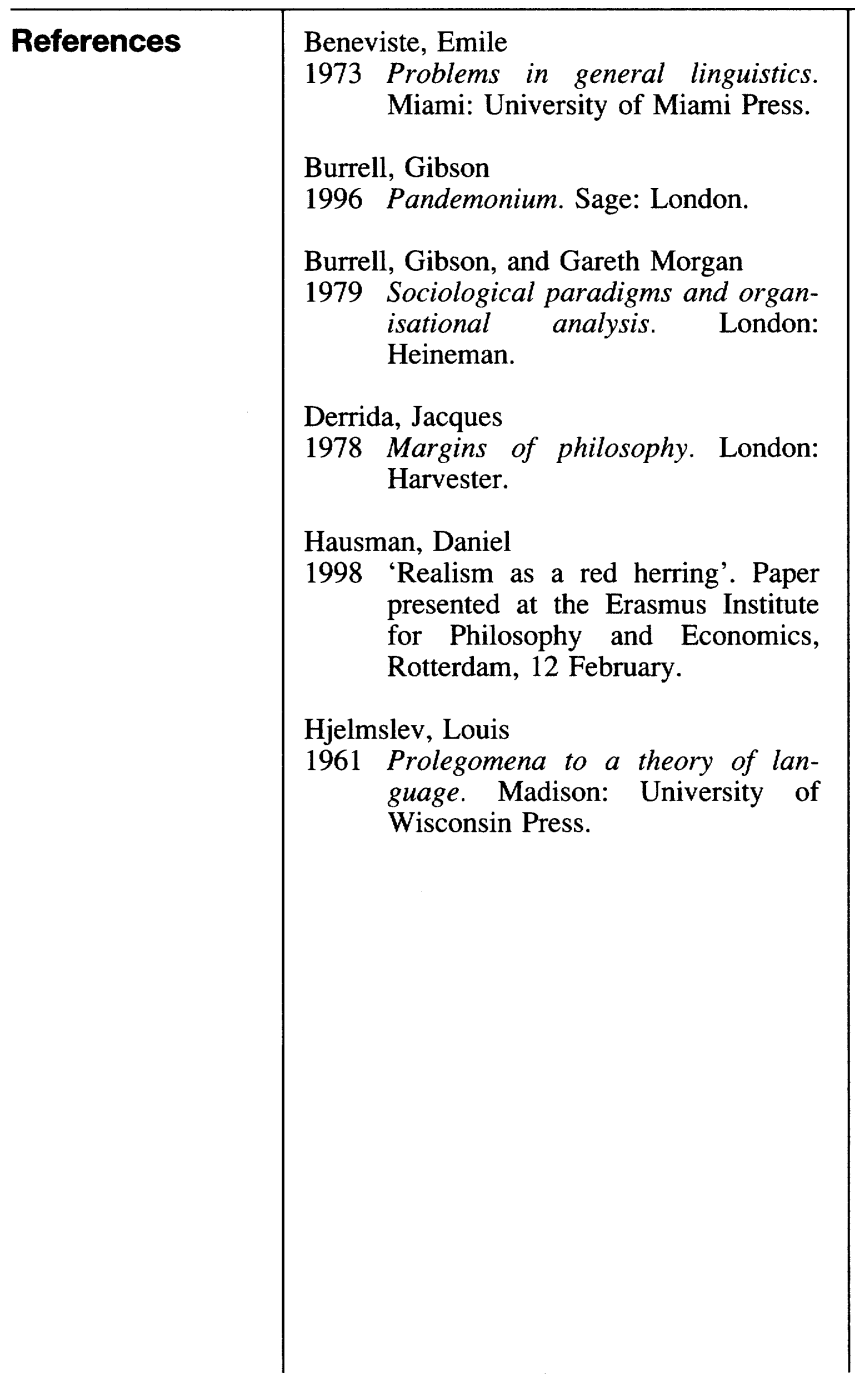

Lawson, Tony

1997 Economics and reality. London: Routledge.

McCourt, Willy

1997 'Discussion note: Using metaphors to understand and to change organizations: A critique of Gareth Morgan's approach'. Organization Studies 18/3: 511-522.

Morgan, Gareth

1986 Images of organisation. London: Sage.

Morgan, Gareth

1993 Imaginization. Newbury Park, CA: Sage

Ricoeur, Paul

1978 The philosophy of Paul Ricoeur. An anthology of his work, edited by C. Reagan and D. Staewart. Boston: Beacon Press. 